\title{
Cloning of an Endangered Species (Bos gaurus) Using Interspecies Nuclear Transfer
}

\author{
ROBERT P. LANZA, ${ }^{1}$ JOSE B. CIBELLI, ${ }^{1}$ FRANCISCA DIAZ, ${ }^{2}$ CARLOS T. MORAES, ${ }^{2}$ \\ PETER W. FARIN, ${ }^{3}$ CHARLOTTE E. FARIN, ${ }^{4}$ CAROLYN J. HAMMER, ${ }^{5}$ \\ MICHAEL D. WEST, ${ }^{1}$ and PHILIP DAMIANI ${ }^{1}$
}

\begin{abstract}
Approximately 100 species become extinct a day. Despite increasing interest in using cloning to rescue endangered species, successful interspecies nuclear transfer has not been previously described, and only a few reports of in vitro embryo formation exist. Here we show that interspecies nuclear transfer can be used to clone an endangered species with normal karyotypic and phenotypic development through implantation and the late stages of fetal growth. Somatic cells from a gaur bull (Bos gaurus), a large wild ox on the verge of extinction, (Species Survival Plan $<100$ animals) were electrofused with enucleated oocytes from domestic cows. Twelve percent of the reconstructed oocytes developed to the blastocyst stage, and $18 \%$ of these embryos developed to the fetal stage when transferred to surrogate mothers. Three of the fetuses were electively removed at days 46 to 54 of gestation, and two continued gestation longer than 180 (ongoing) and 200 days, respectively. Microsatellite marker and cytogenetic analyses confirmed that the nuclear genome of the cloned animals was gaurus in origin. The gaur nuclei were shown to direct normal fetal development, with differentiation into complex tissue and organs, even though the mitochondrial DNA (mtDNA) within all the tissue types evaluated was derived exclusively from the recipient bovine oocytes. These results suggest that somatic cell cloning methods could be used to restore endangered, or even extinct, species and populations.
\end{abstract}

\section{INTRODUCTION}

E XTINCTION THREATENS $11 \%$ of birds, $25 \%$ of mammals, and $34 \%$ of fish species (Alexander, 2000; Porter, 2000). Given current trends, many rare or endangered vertebrate species will soon be lost despite efforts to maintain biodiversity via habitat and wildlife conservation. Even when a species is not endangered or threatened, the loss of biological diversity may lead to extinction of subspecies and other valuable genetic populations (Corley-Smith and Brandhorst, 1999). The current method of preserving genetic diversity of endangered species in captivity is through a series of captive propagation programs. However, these programs are not without

\footnotetext{
${ }^{1}$ Advanced Cell Technology, One Innovation Drive, Worcester, Massachusetts.

${ }^{2}$ Department of Neurology, University of Miami School of Medicine Miami, Florida.

${ }^{3}$ Department of Farm Animal Health \& Resource Management, College of Veterinary Medicine, North Carolina State University, Raleigh, North Carolina.

${ }^{4}$ Department of Animal Science, North Carolina State University, Raleigh, North Carolina.

${ }^{5}$ Department of Animal Science, Iowa State University, Ames, Iowa.
} 
limitations, which include limited physical space for animals, problems with animal husbandry, and general reproductive failure of the animal (Lasley et al., 1994). Recent advances in assisted reproductive techniques such as cryogenics of gametes/embryos, artificial insemination, and embryo transfer have allowed for new methods for the further propagation of endangered species. Most recently, there is growing scientific and public interest in using nuclear transfer techniques to facilitate the rescue of endangered species, or even to restore them after the extinction of intact organisms. However, unlike the cloning of rodents and domestic animals where there is a ready supply of oocytes and surrogate animals, the cloning of highly endangered or extinct species will require the use of an alternative method of cloning known as interspecies nuclear transfer.

Recent in vitro studies have confirmed the ability of bovine oocyte cytoplasm to support mitotic cell cycles under the direction of differentiated somatic cell nuclei of several mammalian species (Dominko et al., 1999; Lanza et al., 1999a, 1999b). Nuclear transfer units between sheep, pigs, monkeys and rats, and enucleated bovine oocytes, all underwent transition to interphase accompanied by nuclear swelling and further progression through the cell cycle as evidenced by successive cell division and formation of a blastocoele cavity at the time appropriate for the species of the donor nuclei. As in other studies, in which nuclei from human somatic cells were transferred into enucleated bovine oocytes, some of the interspecific embryos progressed further and also developed to advanced embryonic stages (Lanza et al., 1999a, 1999b). Furthermore, an attempt at interspecies nuclear transfer with ovine oocytes (Ovis aries) and somatic cells from the argali wild sheep (Ovis ammon) resulted in the production of a few blastocysts. After embryo transfer fluid accumulation was observed in one recipient via ultrasonography although no fetus or heartbeat was detected (White et al., 1999). To date, there has been no evidence that fetal development will result after the fusion of mammalian somatic cells with enucleated xenogenic oocytes. It is also unclear whether the cloned progeny would harbor the mitochondrial DNA (mtDNA) genotype of the recipient cytoplast, as with Dolly the sheep (Evans et al., 1999), and whether mitochondria from a surrogate species are capable of supporting normal embryonic and fetal development.
Here we show that interspecies nuclear transfer can be used to successfully clone an endangered bovid with normal karyotypic and phenotypic development through attachment and the late stages of fetal growth, with differentiation into complex tissues and organs, even though the mtDNA is derived exclusively from another species.

\section{MATERIALS AND METHODS}

\section{Adult gaur cell line derivation}

Dermal fibroblasts were isolated from an adult male gaur (Bos gaurus) at postmortem. A skin biopsy was minced and cultured in Dulbecco's modified Eagle's medium (DMEM) supplemented with $15 \%$ fetal calf serum, L-glutamine (2 $\mathrm{mmol} / \mathrm{L})$, nonessential amino acids $(100 \mu \mathrm{M}), \beta$ mercaptoethanol $(154 \mu \mathrm{M})$, and antibiotics at $38^{\circ} \mathrm{C}$ in a humidified atmosphere of $5 \% \mathrm{CO}_{2}$ and $95 \%$ air. The tissue explants were maintained in culture and a fibroblast cell monolayer established. The cell strain was maintained in culture, passaged twice and cyropreserved in $10 \%$ dimethyl sulfoxide (DMSO) and stored in liquid nitrogen. Donor cells were thawed, cultured, passaged, and further propagated prior to nuclear transfer.

\section{Nuclear transfer and embryo culture}

Bovine (Bos taurus) oocytes were obtained from abattoir-derived ovaries as previously described (Damiani et al., 1996). Oocytes were mechanically enucleated at 18-22 hours postmaturation, and complete enucleation of the metaphase plate confirmed with bisBenzimide (Hoechst 33342) dye under fluorescence microscopy. A suspension of actively dividing gaur cells was prepared immediately prior to nuclear transfer. The cell suspension was centrifuged at $800 \mathrm{~g}$ and $5 \mu \mathrm{L}$ of the resulting cell pellet used for the donor cells. A single cell was selected and transferred into the perivitelline space of the enucleated oocyte. Fusion of the cell-oocyte complexes was accomplished by applying a single pulse of $2.4 \mathrm{kV} / \mathrm{cm}$ for $15 \mu \mathrm{s}$. Fused complexes were chemically activated and cultured as previously described (Cibelli et al., 1998). Cleavage rates were recorded and development to the blastocyst stage was assessed on days 7 and 8 of culture. Resulting blastocysts were nonsurgically transferred into progestrin-synchronized recipients. 


\section{Fetal gaur cell line derivation}

To confirm their genomic origin, three fetuses were sacrificed and collected by cesarean section at $46(n=1)$ and $54(n=2$; twins) days of gestation. Individual fetuses were placed in a sterile container with Dulbecco's phosphate-buffered saline (PBS) supplemented with antibiotic, packed in wet ice, and transported to the laboratory. On arrival at the laboratory, crown-rump lengths (CRL) were recorded and the external morphology was evaluated for gross abnormalities. The left forelimb from each gaur fetus was aseptically removed, minced, and cultured as described above. After 5-10 days, confluent fetal fibroblast cell lines were derived. Cell strains were either subjected to microsatellite marker and cytogenetic analyses, or cryopreserved for long-term storage.

\section{Cytogenetic analysis}

Cells were treated with colcemid $(0.04 \mu \mathrm{g} / \mathrm{mL})$ for 20 minutes at $37^{\circ} \mathrm{C}$ in an atmosphere of $5 \%$ $\mathrm{CO}_{2}$ and $95 \%$ air. After colcemid treatment, cells were trypsinized and centrifuged for 5 minutes at $200 \mathrm{~g}$ and the supernatant removed. Cells were resuspended in a prewarmed hypotonic solution $(0.075 \mathrm{~mol} \mathrm{KCl})$ and incubated at $37^{\circ} \mathrm{C}$ for $12 \mathrm{~min}-$ utes. Cells were then centrifuged and the resulting pellet resuspended in $8 \mathrm{~mL}$ of Carnoy's fixative (3:1 methanol:glacial acetic acid) at room temperature for 30 minutes. Fixed cells were centrifuged and washed twice in fresh Carnoy's fixative. After the last centrifugation, the cells were resuspended in 0.5 to $1.0 \mathrm{~mL}$ of freshly prepared fixative and single drops were placed on clear slides and air-dried. Slides were stained in a stain solution consisting of Wright's stain and $0.06 \mathrm{~mol}$ of phosphate buffer, $\mathrm{pH} 6$ (1:3 ratio per slide). The entire slide was covered with the stain preparation for 3 minutes, rinsed with distilled water, and air-dried. Ten Giemsa-banded cells in metaphase configuration were examined for complete chromosome numbers for each cell line. Five cells in metaphase were photographed and one karyotype constructed and chromosomes arranged in pairs from the largest to smallest.

\section{$m t D N A$ and microsatellite analysis}

Mitochondria DNA was analyzed using two independent methods.

Restriction fragment polymorphism. Approximately $0.25 \mu \mathrm{g}$ of total DNA extracted from dif- ferent tissues by standard procedures (Moraes et al., 1992) were used to amplify a 483-bp fragment from the mtDNA D-loop region. Oligonucleotide sequences corresponded to positions 1602116043 and 165-143 of the Bos taurus mitochondrial genome (GENBANK accession number NC_001567) (Anderson et al., 1982). Although there is variation in the nucleotide sequence between the Bos taurus and Bos gaurus (GENBANK accession number AF083371) (Ward et al., 1999) mtDNA D-loop regions, the oligonucleotide primers have $100 \%$ homology with mtDNA from both species. The amplified fragment was labeled with $\left.{ }^{32} \mathrm{P}\right]-\mathrm{dCTP}$ in the last cycle of the polymerase chain reaction (PCR) to avoid the detection of heteroduplexes (Moraes et al., 1992). Amplicons were digested with SphI or ScrFI and analyzed by polyacrylamide gel electrophoresis (PAGE) and Phosphorimaging (Cyclone, Packard Instruments).

Allele specific PCR. Oligonucleotide primers corresponding to relatively divergent regions of the mtDNA D-loop were used to amplify a $480 \mathrm{bp}$ fragment specifically from taurus or gaurus. The gaurus primers were: forward CATAGTACATGAACTCATTAATCG, and reverse TTGACTGTAATGCCCATGCC. The taurus primers were: forward CATAATACATATAATTATTGACTG, and reverse TTGACTGTAATGTCCATGCT. Amplification was performed with the following cycling program: $94^{\circ} \mathrm{C} 1^{\prime}: 65^{\circ} \mathrm{C} 1^{\prime}: 72^{\circ} \mathrm{C} 1^{\prime}$ for $30 \mathrm{cy}$ cles. Microsatellite analysis of the bovine chromosome 21 (D21S18, Research Genetics) was performed by PCR amplification of the marker after end-labeling one of the oligonucleotide primers with [ $\left.{ }^{32} \mathrm{P}\right]-A T P$. The amplification products were separated in a denaturing PAGE and analyzed by phosphorimaging.

\section{RESULTS}

Karyotype analysis of cells derived from the gaur (Bos gaurus) at postmortem revealed a normal diploid chromosome number of $2 n=58$, made up of a pair of small sex ( $X$ and $Y$ ) submetacentric chromosomes, two larger submetacentric autosomes (different in size), and 54 acrocentric autosomes, most of which could be arranged in pairs in descending order of size (Fig. 1b). In vitro matured bovine (Bos taurus) metaphase II (MII) oocytes were enucleated 18-22 hours after onset of maturation and a total of 692 
embryos reconstructed by nuclear transfer using the donor gaur cells as previously described (Cibelli et al., 1998). Eighty-one blastocysts (12\%) were identified after a week in culture (Fig. 2). Forty-four embryos were transferred into progestin-synchronized recipients, and 8 of the 32 recipients $(25 \%)$ were found to be pregnant by ultrasound 40 days after transfer. Three fetuses

$\mathbf{a}$

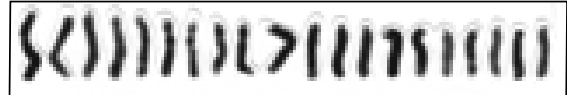

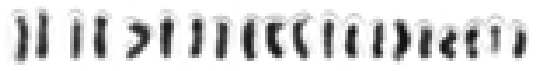
11 $111111, \ldots 11 \ldots$

b

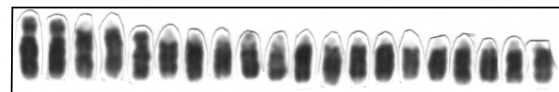
01000000000000000000

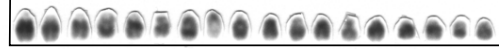

c

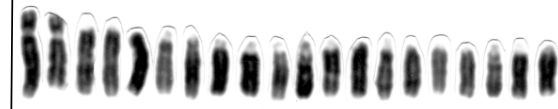

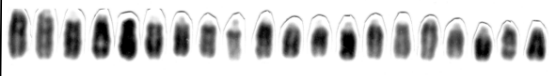
40

d

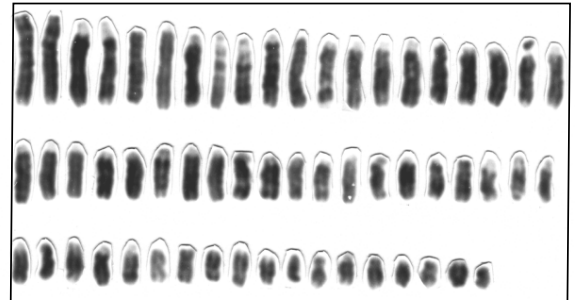

e

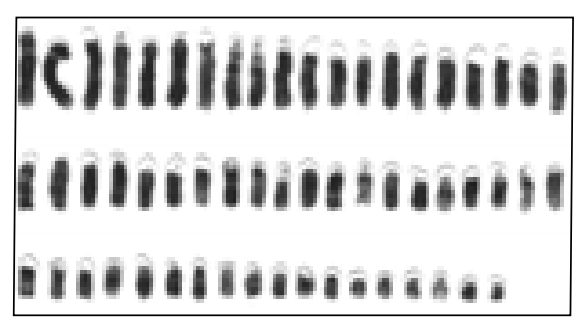

FIG. 1. Karyotype analysis of cloned fetuses. (a) Standard Geimsa-banded karyotype of a male bovine (Bos taurus) displaying 60 chromosome homologues aligned largest to smallest. (b) Standard Geimsa-banded karyotype of a male gaur (Bos gaurus) displaying 58 chromosome homologues aligned largest to smallest. (c-e) Geimsa-banded karyotypes of the three cloned fetuses displaying the 58 chromosome homologues, further indicating their gaurus nuclear origin. were electively removed at days 46 to 54 of gestation (Fig. 3), whereas 6 of the remaining recipients $(75 \%)$ remained pregnant by 2 months of gestation. Four of these animals aborted between days 62 and 70 of gestation, whereas two of the pregnancies continued gestation. One recipient had a late-term abortion at 202 days of gestation (Fig. 4), while the remaining pregnancy is longer than 180 days and currently ongoing (Fig. 5).

Three fetuses were removed by elective cesarean section at days 46 and 54 (twins) of gestation (Fig. 3). CRL recorded at the time of removal were $2.46 \mathrm{~cm}, 4.40 \mathrm{~cm}$, and $4.60 \mathrm{~cm}$ for fetus number 1,2 , and 3 , respectively. The fetuses were evaluated for external morphology. There was no evidence of gross external abnormalities including duplication of structures or tissues or other defects in any of the fetuses. The body of each fetus consisted of a head, trunk, limb buds or limbs, and tail. Normal development appeared to be occurring in the fetuses as evidenced by the presence of a well-defined presumptive mouth, external ears, nose, and eyes. Limb buds were present in fetus number 1 . For fetuses number 2 and 3 , the appendicular tissues appeared normal and included proportional limbs, each with two digits at the distal end (hoof) as well as two dewclaws. These observations suggest that external development of these two fetuses was complete for early gestation.

Fibroblast cell strains were derived from the cloned animals and subjected to microsatellite marker and cytogenetic analyses. Within the family Bovidae, the domestic cattle and many other members have a normal diploid chromosome number of 60 (Fig. 1a), whereas the gaur is unique with a chromosome complement of 58 (Fig. 1b; Riggs et al., 1997; Bongso and Hilmi, 1988). Cytogenetic analysis on the cloned cell strains revealed a normal karyotype with a modal chromosome number of 58 (Fig. 1c-e). A large majority of the cells evaluated from each fetus were within the modal number $(89 \%-92 \%)$. Microsatellite analysis of the bovine chromosome 21 also confirmed that all three fetuses had gaurus nuclear background (Fig. 6).

The origin of mtDNA in the nuclear transferderived fetuses was determined by the analyses of polymorphic markers. mtDNA from the 11 different tissue types tested (brain, liver, muscle, eye, gonad, heart, intestine, lung, skin, tongue, and kidney) was exclusively taurus (Fig. 7). No gaurus mtDNA could be observed in tissues from any of the three fetuses using two different re- 
a

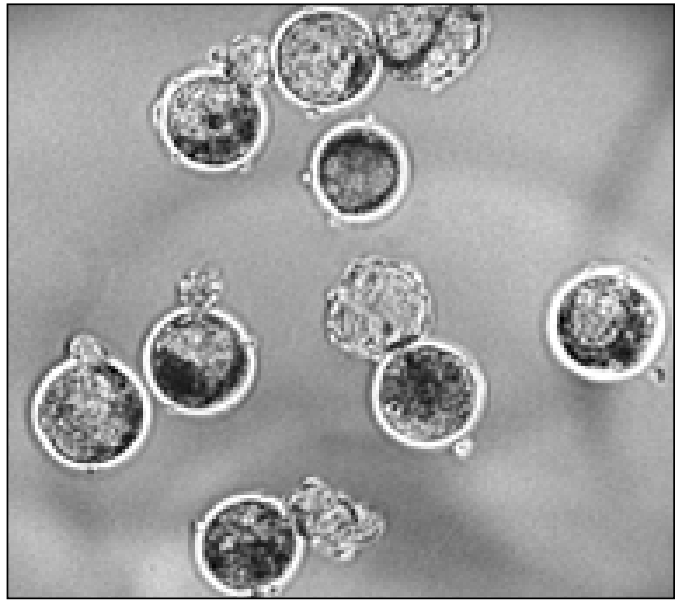

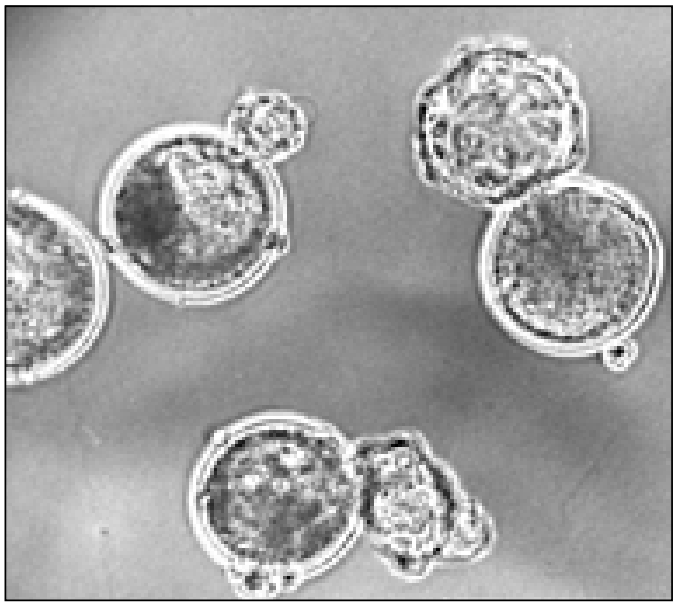

FIG. 2. Embryos derived from cross-species nuclear transfer. (a) Gaur embryos at the blastocyst-stage of development following 7 days of in vitro culture, prior to embryo transfer (100× magnification). (b) Hatching blastocysts derived from cross-species nuclear transfer $(200 \times$ magnification).

$\mathbf{a}$

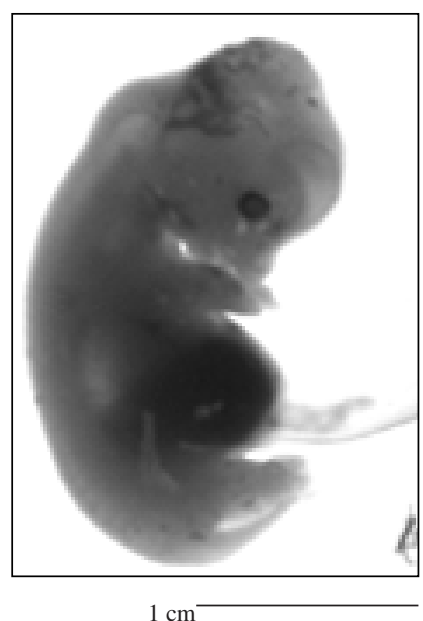

b

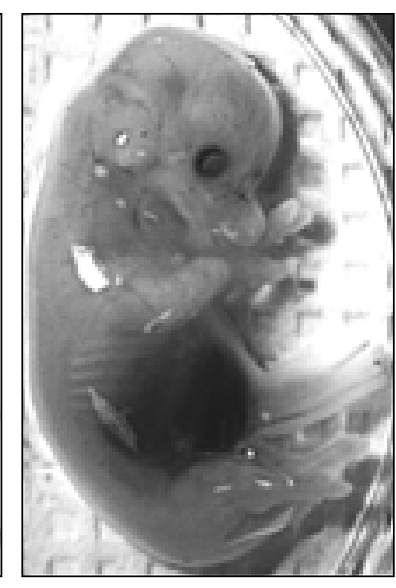

$1 \mathrm{~cm}$ c

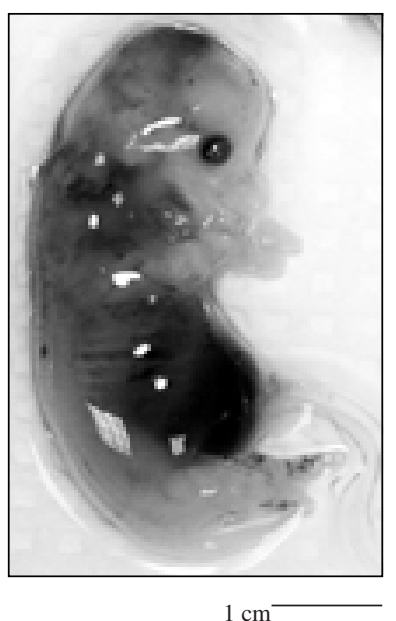

d

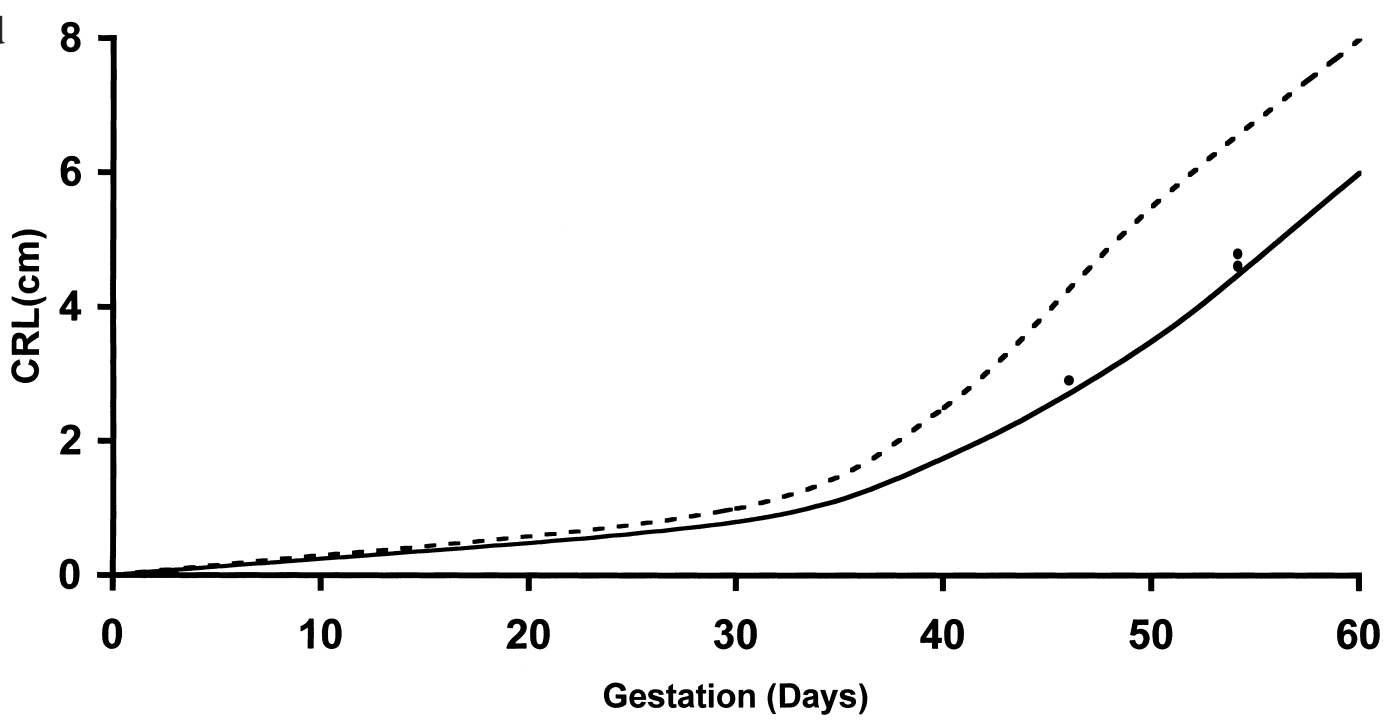

FIG. 3. Representation of nuclear transfer-derived fetuses. (a) Cloned fetus removed at 46 days of gestation. (b-c) Cloned fetuses removed at 54 days of gestation. (d) Normal growth curve of bovine fetuses (adapted from Evans and Sachs, 1973). Dashed line represents crown rump length of beef breeds of cattle. Solid line represents crown-rump length of dairy breeds of cattle. $\bullet$, Crown-rump lengths of the nuclear transfer-derived fetuses. 
a

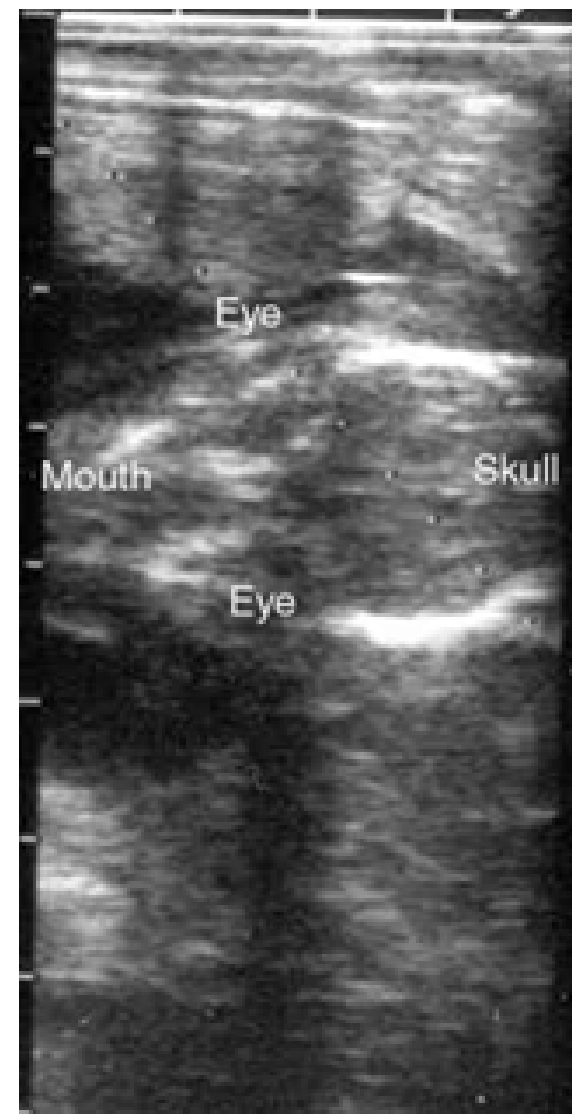

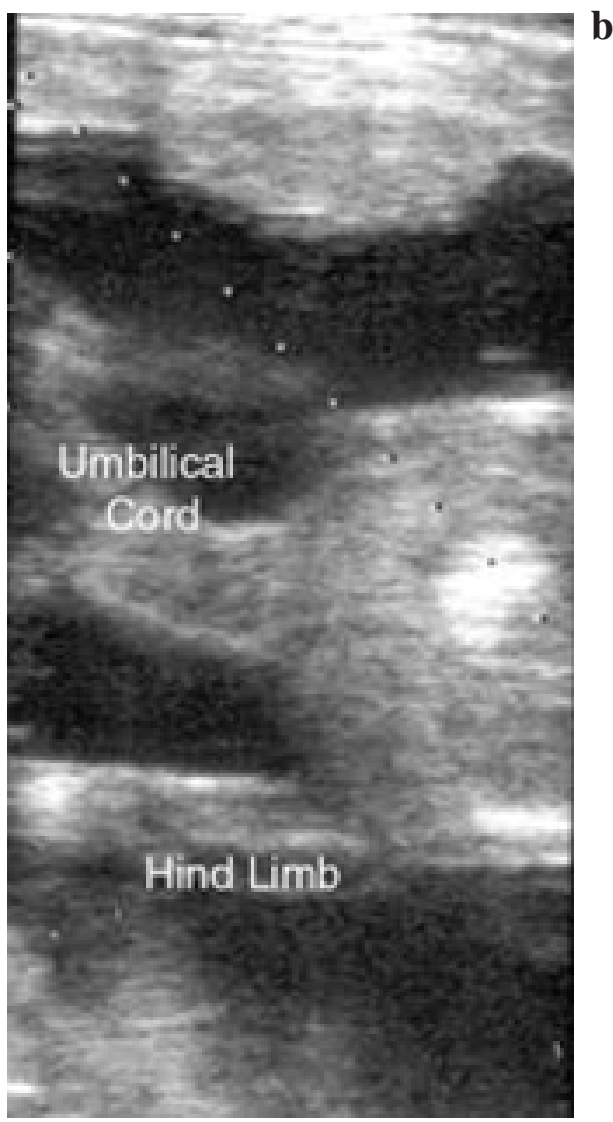

FIG. 4. Ultrasound images of gaur fetus at 80 days of gestation. (a) Longitudinal cross section of the cranium, displaying the frontal bones (skull), maxillary (mouth), and the orbits (eye). (b) Longitudinal cross section of the posterior region displaying hindlimb and umbilicus.

striction fragment length polymorphisms (Fig. 8a and $8 \mathrm{~b}$ ). The use of allele-specific PCR confirmed the PCR/RFLP results showing exclusively taurus mtDNA (not shown). We estimate the PCR/RFLP assay to be able to detect down to $1 \%$ of gaurus mtDNA. Serial ten-fold dilutions of purified gaurus DNA templates also showed that the allele-specific PCR has a detection limit of approximately $1 \%$ of gaurus mtDNA. There are approximately $2-5 \times 10^{3}$ molecules of mtDNA in a somatic cell (Evans et al., 1999) as compared to approximately $1 \times 10^{5}$ molecules in an oocyte (Piko and Taylor, 1987). Therefore, if every molecule of donor mtDNA had survived and replicated equally, there should be approximately $2 \%-5 \%$ gaurus mtDNA in the nuclear transfer-derived tissues. The fact that there was no detectable contribution from the donor gaur cells is consistent with results obtained in sheep produced by intraspecific nuclear transfer. The mtDNA of each of 10 cloned sheep, including Dolly, the first animal cloned from an adult somatic cell, was ex- clusively oocyte-derived, even though nuclear transfer was also performed by whole-cell fusion of somatic cells with enucleated oocytes (Evans et al., 1999).

One fetus and a partial placental unit were recovered after a late term abortion at 202 days of gestation (Fig. 4). CRL and body weight of the male fetus was recorded and were $63.5 \mathrm{~cm}$ and $10.7 \mathrm{~kg}$, respectively. The fetus was evaluated for overall external morphology and skeletal and internal organs were measured. As with the earlier recovered fetuses, external skeletal and internal organs appeared to be normal for its gestational age and there was no evidence of external or internal abnormalities. Cranial development appeared normal with a head circumference of 37.1 $\mathrm{cm}$. Tactile hair was present on the chin; both the ears and eyes were well defined. The eyelid had begun to separate and eyelashes were present. Development of the body and appendages were within normal limits for in vitro produced embryos (Farin and Farin, 1995). Hearthgirth was 


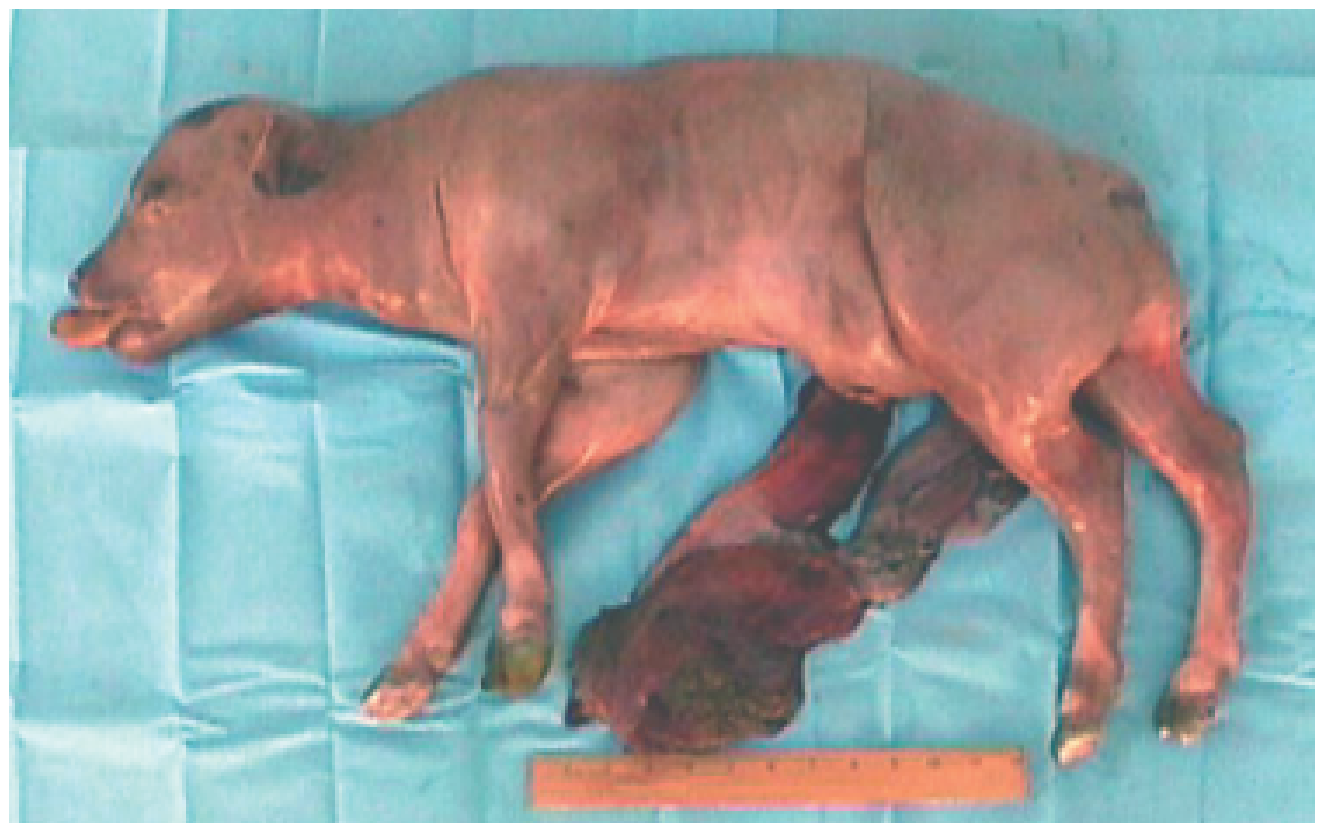

FIG. 5. Photograph of gaur fetus recovered following late-term abortion at 202 days of gestation. External and internal morphology of animal appeared normal and displayed no gross abnormalities. Ruler bar represents $30 \mathrm{~cm}$.

$47.0 \mathrm{~cm}$ and the forelimbs were proportional with the right metacarpus and metatarsus measuring 9.1 and $9.6 \mathrm{~cm}$, respectively. The right hip-fetlock length was $29.0 \mathrm{~cm}$ and the circumferences of the fetlock and pastern were 10.2 and $8.9 \mathrm{~cm}$, respectively. All limbs contained defined hooves and dewclaws that had started to harden. The scrotum was present and descent of the testes had occurred and tail tip hair was also observed. The weights of the internal organs, including the heart, liver, lungs, and kidneys, were within normal limits $(72.86,215.9,134.1$, and $110.5 \mathrm{~g}$, respectively). The animal appeared to be following a normal developmental course and the failure of the pregnancy was likely due to placentation. Gross examination of the placental tissue sug-

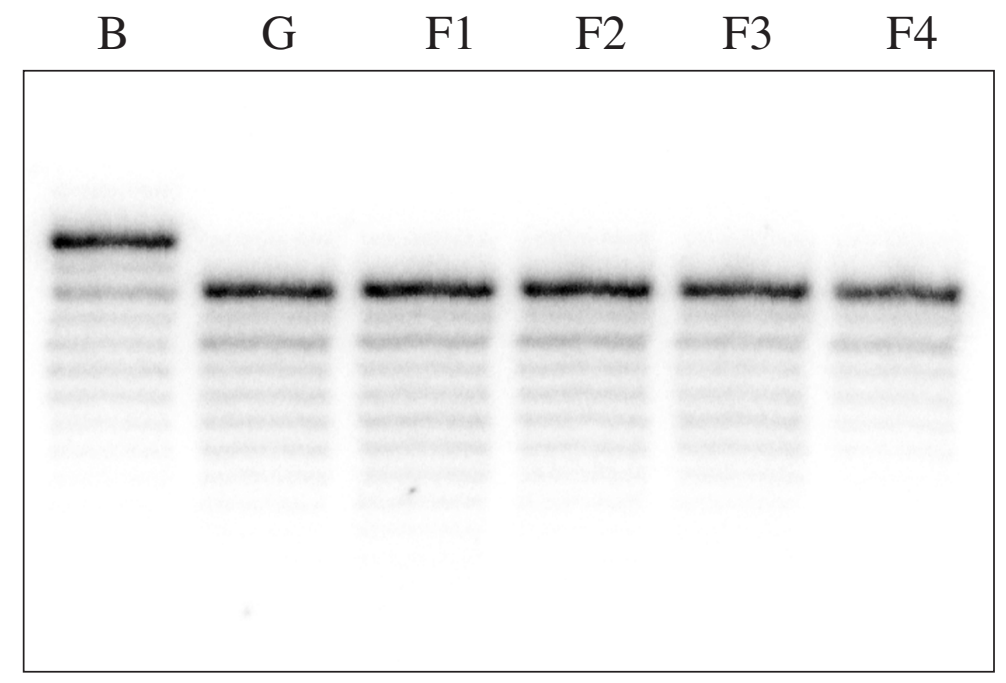

FIG. 6. Microsatellite analyses of bovine and gaur fibroblast cell lines assayed with bovine chromosome 21 specific probe. All four cloned fetuses (three electively removed fetuses and the fetus recovered following late-term abortion at 202 days) were derived from gaurus nuclear DNA. Bovine fibroblast (B), donor gaur fibroblast (G), and fetal gaur fibroblast (F). 


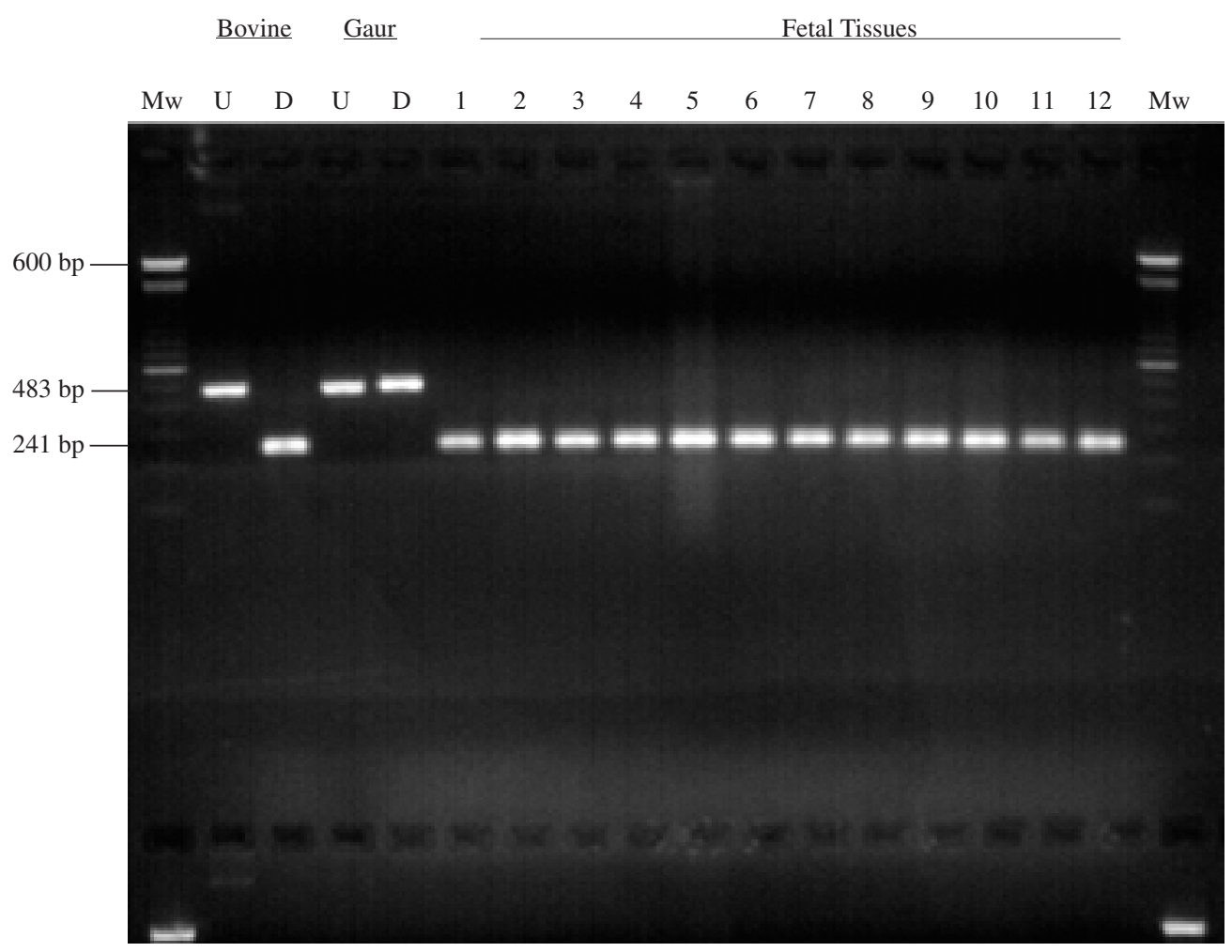

FIG. 7. Ethidium bromide-stained agarose gel of restriction digests of bovine and gaur mitochondrial DNA (mtDNA). Total DNA was isolated from adult bovine and gaur fibroblast cells and the D-loop region of mtDNA amplified. The D-loop regions of fetal gaur mtDNA were amplified from DNA isolated from twelve tissue types (1-12; brain, eye, tongue, bone, heart, intestine, liver, kidney, gonad, muscle, skin, hoof). The amplified fragments of mtDNA were digested with restriction enzyme BstNI, and electrophoresed through an agarose gel. mtDNA analyses revealed that all tissue types derived from cloned fetuses were Bos taurus in origin and had undetectable levels of gaurus mtDNA. U, undigested polymerase chain reaction (PCR) fragment; D, digested fragment.

gested a reduced number of cotyledons. These findings are consistent with previously published reports for cloned animals (Keefer et al., 1994; Wilson et al., 1995; Garry et al., 1996; Stice et al., 1996; Galton et al., 1998; Renard et al., 1999; Solter and Gearhart, 1999). Nuclear (Fig. 7) and mitochondrial DNA analysis by allele-specific PCR (not shown) confirmed the results observed in the previous three fetuses.

\section{DISCUSSION}

The cloning of an animal with the nuclear genome of one species and the mitochondrial genome of another species has not been previously reported. It has been shown that during intraspecific crosses of mice, the paternal mtDNA can be maintained in the offspring (Kaneda et al., 1995). Microinjected Mus spretus mitochondria into Mus musculus oocytes were also maintained in a heteroplasmic state in mice (Irwin et al., 1999). Other studies, however, showed that interspecific paternal mtDNA was selected against during early murine development (Shitara et al., 1998). Similarly, interspecific mtDNA was not preferentially replicated after embryonic nuclear transfer between subspecies of cattle, in which blastomeres from Bos taurus indicus embryos were fused to Bos taurus taurus oocytes (Meirelles et al., 1999). In addition, based on somatic cell experiments, we would expect a preferential maintenance of a gaurus mtDNA in the clones. In cultured cells, it was shown that the human nucleus has a strong preference for the maintenance of cognate mtDNA in cells containing both human and gorilla, or human and chimpanzee mtDNA (Moraes et al., 1999). The fact that gaurus mtDNA was not maintained, or even amplified, in the fetuses suggests that sequence variations between gaurus and taurus mtDNA are relatively neutral at the functional level and the fusion product 

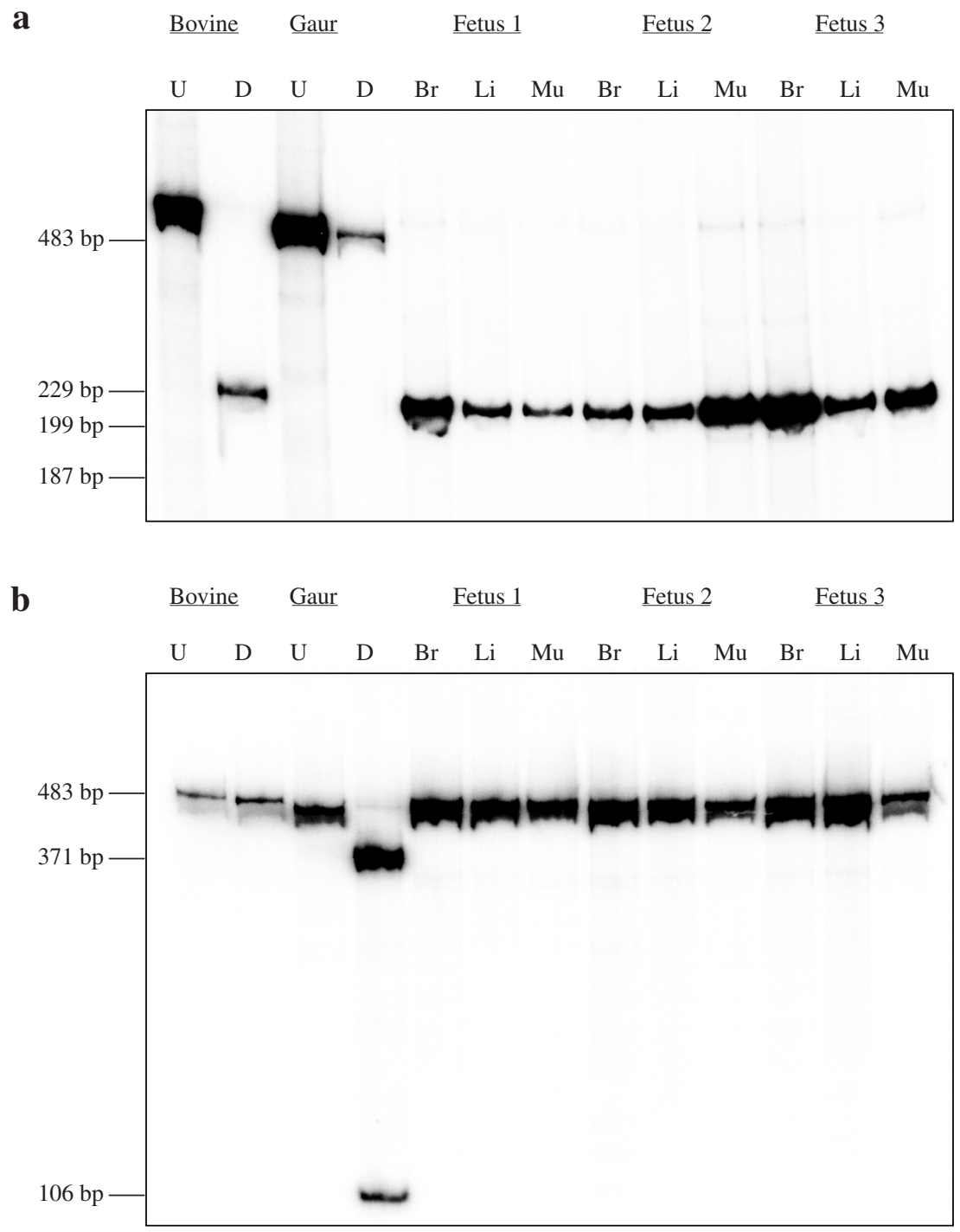

FIG. 8. Interspecific clones do not retain the nuclear cognate mitochondrial DNA (mtDNA). Total DNA was extracted from bovine fibroblasts, gaur fibroblasts, and tissues (brain, liver and skeletal muscle) from the three cloned fetuses (fetus 1-3) and used to amplify a 483-bp fragment corresponding to the mtDNA D-loop region. This fragment was labeled with [32P]-dCTP in the last cycle of the polymerase chain reaction (PCR) (Cibelli et al., 1998), digested with ScrFI (a) or SphI (b) and electrophoresed through a 10\% polyacrylamide gel. Phosphorimage analyses showed that the three different tissues from the three fetuses have undetectable levels of gaur mtDNA. U, undigested PCR fragment; D, digested with respective restriction endonucleases. Molecular weights are shown on the left of each panel.

would behave as a fertilized egg, eliminating the exogenous mtDNA (Kaneda et al., 1995). A segment of the highly polymorphic D-loop region of mtDNA is $85 \%$ identical between taurus and gaurus, and the nucleotide sequences of the genes for cytochrome b and cytochrome oxidase subunit II are $93 \%$ and $94 \%$ identical. This high degree of identity probably results in a lack of preferential maintenance of gaurus mtDNA in the crossspecies cloned fetuses. It is difficult to predict the mtDNA segregation pattern when cross-species cloning is attempted between more divergent species. These essential nuclear-mitochondrial interactions have been shown to occur, not only between different species, but also between different genera, up to approximately 8-18 million years after species radiation (Kenyon and Moraes, 1997). However, it is possible that with increasing divergency, functional problems related to nucleo-cytoplasmic compatibility could arise (Barrientos et al., 1998). Steinborn et al. (2000) found that some intraspecific bovine clones 
can maintain a very small percentage of the nuclear-derived mtDNA (e.g., 0.4\%). Because the detection limit of our techniques is approximately $1 \%$, we may have missed lower amounts of gaurus mtDNA in the fetuses.

Based on the presence of key external features including craniofacial structures (eyes, ears, mandible, tongue), as well as limbs, vertebrae, ribs, and tail in these cloned gaur fetuses, development appeared to be normal for fetuses of the Bos genus. This would imply, first, that the tissue interactions between developing hypoblast and epiblast, and subsequently between endoderm, ectoderm, and mesoderm did occur appropriately during gastrulation and neurulation in these fetuses (Noden and Lahunta, 1985). Second, these observations suggest that subsequent development of the head, face, and limbs also followed a normal pattern. Little information is available on the detailed processes involved in differentiation of external morphological structures in fetuses of the Bos genus; and, of Bos gaurus (gaur) fetuses. However, considerable information is available regarding molecular and cellular mechanisms responsible for controlling development in the other mammalian species including the mouse. The presence of apparently normal craniofacial development present in these gaur fetuses would be consistent with the proper expression of cognates of the murine group-I aristaless-related genes (Meijlink et al., 1999). Similarly, development of limb buds (fetus 1) and whole limbs in the fetuses is consistent with the assumption of appropriate development and interactions of the apical ectodermal ridge and progress zone for the establishment of correct patterns for proximaldistal development of the fore and hindlimb skeletal structures (Johnson and Tabin, 1997). Molecular regulation of these processes clearly would involve appropriate expression of bovine cognates of fibroblast growth factor genes including FGF-10, FGF-8, FGF-4, FGF-2, as well as cognates of sonic hedgehog (Shh), Wnt-7a, and members of the HoxA and HoxD gene families (Johnson and Tabin, 1997).

Our findings confirm the ability of xenogenic oocyte mitochondria to support normal karyotypic and phenotypic development to the late fetal stages under the direction of differentiated somatic cell nuclei of an endangered mammalian species. However, it is unclear if the interspecies cloning procedure will further increase the risk of developmental problems associated with late- fetal and neonatal development. Although, interspecific embryo transfer of gaur embryos to domestic cattle have resulted in the birth of live calves (Stover et al., 1981; Johnston et al., 1994), one study has reported high rates of mortality of calves within 1 week of birth and suggested that the physiological complications were attributed to interspecies incompatibilities (Loskutoff et al., 2000).

In summary, the present study provides the first evidence that fetal mammals can be generated using interspecies nuclear transfer. Although the cloned fetuses are authentic nuclear (gaur) clones, they are in fact genetic chimeras with oocyte-derived mtDNA. However, since mtDNA is transmitted by maternal inheritance, we would predict that breeding of any resultant male offspring would lead to genetically pure animals. There is also the possibility if using "reverse cloning" to generate cows with gaur mtDNA as a source of oocytes for nuclear transfer. The ability to carry out successful crossspecies nuclear transfer would open the way for a new strategy on the part of conservation planners to help stem the loss of valuable biological diversity and to respond to the challenge of largescale extinctions ahead. This emerging technology also underscores the need to preserve and expand repositories of normal cell lines from species at risk of extinction.

\section{ACKNOWLEDGMENTS}

We thank C. Blackwell, K. Cunniff, N. Sawyer, K. Delegge, C. Malcuit, and J. Kane (ACT); H. Tyler (Iowa State University), and the staff at Trans Ova Genetics, particularly the Genetic Advancement Center Team. We also thank K. Beck (RESCU) for the gift of the gaur cells and Applied Genetics Laboratories and M. Garcia for their help with the karyotype analysis. Part of this work was supported by the SOMA Foundation and NIH Grant GM55766 (to C.T.M.).

\section{REFERENCES}

Alexander, C.P. (2000). Death row. Time 155, 75-78.

Anderson, S., de Bruijn, M.H., Coulson, A.R., Eperon, I.C., Sanger, F., and Young, I.G. (1982). Complete sequence of bovine mitochondrial DNA. Conserved features of the mammalian mitochondrial genome. J. Mol. Biol. 156, 683-717. 
Barrientos, A., Kenyon, L., and Moraes, C.T. (1998). Human xenomitochondrial cybrids. Cellular models of mitochondrial complex I deficiency. J. Biol. Chem. 5 273, 14210-14217.

Bongso, T.A., and Hilmi, M. (1988). Chromosomes of gaur cross domestic cattle hybrids. Res. Vet. Sci. 44, 251-254.

Cibelli, J.B., Stice, S.L., Golueke, P.J., Kane, J.J., Jerry, J., Blackwell, C., Ponce de Leon, F.A., and Robl, J.M. (1998). Cloned transgenic calves produced from nonquiescent fetal fibroblasts. Science 280, 1256-1258.

Corley-Smith, G.E., and Brandhorst, B.P. (1999). Preservation of endangered species and populations: a role for genome banking. Somatic cell cloning, and androgenesis? Mol. Reprod. Dev. 53, 363-367.

Damiani, P., Fissore, R.A., Cibelli, J.B., Long, C.R., Balise, J.J., Robl, J.M., and Duby, R.T. (1996). Evaluation of developmental competence, nuclear and ooplasmic maturation of calf oocytes. Mol. Reprod. Dev. 45, 521-534.

Dominko, T., Mitalipova, M., Haley, B., Beyhan, Z., Memili, E., McKusick, B., and First, N.L. (1999). Bovine oocyte cytoplasm supports development of embryos produced by nuclear transfer of somatic cell nuclei from various mammalian species. Biol. Reprod. 60, 1496-1502.

Evans, M.J., Gurer, C., Loike, J.D., Wilmut, I., Schnieke, A.E., and Schon, E.A. (1999). Mitochondrial DNA genotypes in nuclear-transfer-derived cloned sheep. Nat. Genet. 23, 90-93.

Evans, H.E., and Sach, W.O. (1973). Prenatal development of domestic and laboratory mammals: growth curves external features and selected references. Zentralbl Veterinarmed 2, 11-45.

Farin, P.W., and Farin, C.E. (1995). Transfer of bovine embryos produced in vivo or in vitro: Survival and fetal development. Biol. Reprod. 52, 676-682.

Galton, D.J., Kay, A., and Cavanna, J.S. (1998). Human cloning: safety is the issue. Nat. Med. 4, 644.

Garry, F.B., Adams, R., McCann, J.P., and Odde, K.G. (1996). Postnatal characteristics of calves produced by nuclear transfer cloning. Theriogenology 45, 141-152.

Irwin, M.H., Johnson, L.W., and Pinkert, C.A. (1999). Isolation and microinjection of somatic cell-derived mitochondria and germline heteroplasmy in transmitochondrial mice. Transgenic Res 8, 119-123.

Johnson, R.L., and Tabin, C.J. (1997). Molecular models for vertebrate limb development. Cell 90, 979-990.

Johnston, L.A., Parrish, J.J., Monson, R., Leibfried-Rutledge, L., Susko-Parrish, J.L., Northey, D.L., Rutledge, J.J., and Simmons, L.G. (1994). Oocyte maturation, fertilization and embryo development in vitro and in vivo in the gaur (Bos gaurus). J. Reprod. Fertil. 100, 131-136.

Kaneda, H., Hayashi, J., Takahama, S., Taya, C., Lindahl, K.F., and Yonekawa, H. (1995). Elimination of paternal mitochondrial DNA in intraspecific crosses during early mouse embryogenesis. Proc. Natl. Acad. Sci. USA 92, 4542-4546.

Keefer, C.L., Stice, S.L., and Matthews, D.L. (1994). Bovine inner cell mass cells as donor nuclei in the production of nuclear transfer embryos and calves. Biol. Reprod. 50, 935-939.

Kenyon, L., and Moraes, C.T. (1997). Expanding the func- tional human mitochondrial DNA database by the establishment of primate xenomitochondrial cybrids. Proc. Natl. Acad. Sci. USA 94, 9131-9135.

Lanza, R.L., Cibelli, J.B., and West, M.D. (1999a). Human therapeutic cloning. Nat. Med. 5, 975-977.

Lanza, R.P., Cibelli, J.B., and West, M.D. (1999b). Prospects for use of nuclear transfer in human transplantation. Nat. Biotech. 17, 1171-1174.

Lasley, B.L., Loskutoff, N.M., and Anderson, G.B. (1994). The limitations of conventional breeding programs and the need and promise of assisted reproduction in nondomestic species. Theriogenology 41, 119-132.

Loskutoff, N.M., Armstrong, D.L., Ohlrichs, C.L., Johnson, D.L., Funk, D.J., VanRoekel, P.V., Molina, J.A., Lindsey, B.R., Looney, C.R., Bellow, S.M., Hammer, C.J., Tyler, H.D., and Simmons, L.G. (2000). Transvaginal ultrasound-guided oocyte retrieval and the development competence of in vitro-produced embryos in vitro and in vitro and in vivo in the gaur (Bos gaurus). Theriogenology 53, 337.

Meijlink, F., Beverdam, A., Brouwer, A., Oosterveen, T.C., and Berge, D.T. (1999). Vertebrate aristaless-related genes. Int. J. Dev. Biol. 43, 651-663.

Meirelles, F.V., Bordignon, V., Watanabe, Y.F., Watanabe, M.R., Dayan, A., Lobo, R.B., Garcia, J.M., and Smith, L.C. (1999). Zygote reconstructions among Bos indicus and Bos taurus cattle and consequences on mitochondrial inheritance. Theriogenology 51, 209.

Moraes, C.T., Kenyon, L., and Hao, H. (1999). Mechanisms of human mitochondrial DNA maintenance: the determining role of primary sequence and length over function. Mol. Biol. Cell. 10, 3345-3356.

Moraes, C.T., Ricci, E., Bonilla, E., DiMauro, S., and Schon, E.A. (1992). The mitochondrial tRNA (Leu(UUR)) mutation in mitochondrial encephalomyopathy, lactic acidosis, and strokelike episodes (MELAS): Genetic, biochemical, and morphological correlations in skeletal muscle. Am. J. Hum. Genet. 50, 934-949.

Noden, D.M., and de Lahunta, A. (1985). The Embryology of Domestic Animals. Baltimore: Williams \& Wilkins. 367 pp.

Piko, L., and Taylor, K.D. (1987). Amounts of mitochondrial DNA and abundance of some mitochondrial gene transcripts in early mouse embryos. Dev. Biol. 2, 364374.

Porter, S. (2000). Biodiversity projections look grim. World Watch 13, 8 .

Renard, J.P., Chastant, S., Chesne, P., Richard, C., Marchal, J., Cordonnier, N., Chavatte, P., and Vignon, X. (1999). Lymphoid hypoplasia and somatic cloning. Lancet 353, 1489-1491.

Riggs, P.K., Owens, K.E., Rexroad, C.E., Amarai, M.E.J., and Womack, J.E. (1997). Development and initial characterization of a Bos taurus X B. gaurus interspecific hybrid backcross panel. J. Heredity 88, 373-379.

Shitara, H., Hayashi, J.I., Takahama, S., Kaneda, H., and Yonekawa, H. (1998). Maternal inheritance of mouse mtDNA in interspecific hybrids: Segregation of the leaked paternal mtDNA followed by the prevention of subsequent paternal leakage. Genetics 148, 851-857. 
Solter, D., and Gearhart, J. (1999). Putting stem cells to work. Science 283, 1468-1470.

Steinborn, R., Schinogl, P., Zakhartchenko, V., Achmann, R., Schernthaner, W., Stojkovic, M., Wolf, E., Muller, M., and Brem, G. (2000). Mitochondrial DNA heteroplasmy in cloned cattle produced by fetal and adult cell cloning. Nat. Genet. 25, 255-257.

Stice, S.L., Strelchenko, N.S., Keefer, C.L., and Matthews, L. (1996). Pluripotent bovine embryonic cell lines direct embryonic development following nuclear transfer. Biol. Reprod. 54, 100-110.

Stover, J., Evans, J., and Dolensek, E.P. (1981). Interspecies embryo transfer from the gaur to domestic Holstein. Proc. Am. Assoc. Zoo Vet. 122-124.

Ward, T.J., Bielawski, J.P., Davis, S.K., Templeton, J.W., and Derr, J.N. (1999). Identification of domestic cattle hybrids in wild cattle and bison species: A general approach using mtDNA markers and the parametric bootstrap. Anim. Conserv. 2, 51-57.

White, K.L., Bunch, T.D., Mitalipov, S., and Reed, W.A. (1999). Establishment of pregnancy after the transfer of nuclear transfer embryos produced from the fusion of Argali (Ovis ammon) nuclei into domestic sheep (Orvis aries) enucleated oocytes. Cloning 1, 47-54.

Wilson, J.M., Williams, J.D., Bondioli, K.R., Looney, C.R., Westhusin, M.E., and McCalla, D.F. (1995). Comparison of birthweight and growth characteristics of bovine calves produced by nuclear transfer (cloning), embryo transfer and natural mating. Anim. Reprod. Sci. 38, 7383.

Address reprint requests to: Robert P. Lanza, M.D. Advanced Cell Technology One Innovation Drive Worcester, MA 01605

E-mail: rlanza@advancedcell.com

Received for publication June 23, 2000; accepted after revision August 15, 2000. 